\title{
КОНСТРУКТИВНІ РІШЕННЯ СУЧАСНИХ ВЕЛИКОПРОЛІТНИХ ТРУБОБЕТОННИХ АРКОВИХ МОСТІВ
}

\section{CONSTRUCTION SOLUTIONS OF MODERN LARGE-SPAN TUBE- CONCRETE ARCH BRIDGES}

Коломійчук Г.П., к.т.н., доцент, Майстренко О.Ф., к.т.н., доцент, Коломійчук В.Г., аспірант, Коломійчук В.Г., студентка (Одеська державна академія будівництва та архітектури, м. Одеса)

Kolomiychuk G.P., Ph.D. in Engineering, Associate Professor, Maistrenko O.F., Ph.D. in Engineering, Associate Professor, Kolomiychuk V.G., postgraduate student, Kolomiychuk V.G., student (Odessa State Academy Civil Engineering and Architecture, Odessa)

Ефективність сучасних аркових мостів досягається новими конструктивними рішеннями. Розглянуті приклади мостів щзо отримали найбільш високу очінку під час експлуатащіi,, $i$ наведені перспективні напрямки для подальшого дослідження та розвитку аркових мостів $з$ використанням трубобетону.

The effectiveness of modern arch bridges is achieved by new design solutions. The considered examples of bridges that received the highest rating during operation, and promising areas for further research and development of arch bridges using pipe concrete are given.

Large-span arched structures have significant potential bearing capacity and can be used as structures to solve the problems of new construction and reconstruction of buildings and structures. They are able to change the uniformity of the environment with their architectural appeal. Arches are especially convenient for use as bearing structures of bridges in mountainous areas where the problem of thrust is solved. The introduction of tube-concrete in the design of arches gave impetus to their further study and effective practical application.

Constructive solutions of modern tube-concrete arch bridges are constantly changing. This is caused by the need to increase the overall dimensions of structures, as well as the introduction of new ultrastrong materials and scientific developments into the construction.

Tube-concrete is not only a durable and load-resistant structural material, but also economical in the process of manufacturing and operation. A metal tube is the external surface of the structure that is being built and can have various processing performed in the factory. The manufacture of formwork from metal tubes allows you to make the dimensions, shape and configuration different depending on the requirements of the project. 
In the future, large-span tube-concrete arch bridges should be used for high-speed rail. Such bridges with a rigid skeleton are insensitive to daily temperature fluctuations and have good durability.

Even though there is success in the design and construction of tube-concrete arch bridges, existing technologies still cannot satisfy existing needs. Thus, it is necessary to constantly search for new design solutions and solve critical issues of improving the fatigue characteristics of welded joints, optimizing the concrete segments, and further reducing the weight of the structure, which will help increase the span.

The article examined a large number of tube-concrete arch bridges and studied their design solutions. It can be concluded that today there is no single methodology for designing sufficiently promising arch bridges, therefore this problem is relevant and requires further study.

Ключові слова: арковий міст, трубобетонні арки, конструктивні рішення, трубобетон, реактивний порошковий бетон.

Keywords: arch bridge, tube-concrete arches, structural solutions, tube-concrete, reactive powder concrete.

Вступ. Великопролітні аркові конструкції володіють значним потенціалом несучої здатності i можуть застосовуватися в якості конструкцій, що вирішують проблеми нового будівництва та реконструкції будівель та споруд. Вони здатні змінити одноманітність навколишнього середовища своєю архітектурною привабливістю. Особливо зручні арки для використання в якості несучих конструкцій мостів в гористих місцевостях, де вирішується проблема розпору. Впровадження в конструкції арок трубобетону дало поштовх для їх подальшого вивчення i ефективного практичного застосування.

Аналіз останніх досліджень та публікацій. Серед побудованих та запроектованих аркових мостів існують такі, що можна віднести до найбільш унікальних з точки зору конструктивних рішень.

Арковий міст «Немовля Енріко» в Порто володіє високими технічними та естетичними якостями i приставляє собою найкращий зразок геометричних параметрів для моніторингу інших аркових мостів $[1,2]$. Слід виділити, що він входить в четвірку найбільших аркових мостів Свропи 3 прольотом L $=280$ м. Відношення прольоту до товщини арки ( $\mathrm{h}=1,5$ м) складає 187 i є світовим рекордом, тобто це дуже тонка арка. Стріла підйому арки складає $\mathrm{f}=25$ м. Відношення $\mathrm{L} / \mathrm{f}=11,2$ показує що цей міст досить пологий. Його «статичний коефіцієнт» ( $\left.\mathrm{L}^{2} / \mathrm{f}>3000\right)$, котрий прямо пропорційний осьовому зусиллю, що діє в склепінні арки, $\epsilon$ найбільшим із усіх арок, побудованих до теперішнього часу.

Дійсно, арка мосту «Немовля Енріке» в Порто є найнавантаженішою i найделікатнішою у світі.

Останнім часом відбувається еволюція конструктивного дизайну та технологій будівництва [3]. Технологічний розвиток не обійшов сферу високоміцних матеріалів, таких як композитний матеріал на основі 
портландцементу, що отримав назву - реактивний порошковий бетон (РПК). Цей матеріал може досягати міцності на стиск від 200 до $800 \mathrm{MПа}$ та використовуватися в будівництві мостів. Розроблено проектні рішення для аркових мостів прольотом 500 м, 750 м та 1000 м. За винятком мостових фундаментів та примикань, всі несучі елементи конструкцій виготовляються 3 РПК. Витрати РПК на виконання всіх мостових елементів без примикань та фундаментів становлять $98957 /(1320 * 35,5)=$ $=2,11 \mathrm{~m}^{3} / \mathrm{m}^{2}$ для арки прольотом $1000 \mathrm{M}, \mathrm{i} 1,75 \mathrm{~m}^{3} / \mathrm{m}^{2}$ для арки прольотом $750 \mathrm{M}$.

В науковій роботі [4] виконано експериментально-теоретичні дослідження трубобетонних аркових мостів. Для проектування розроблено спрощений метод прогнозування довгострокової реакції аркових трубобетонних мостів, що враховує старіння бетону та процес будівництва. На моделях арок досліджено деформації попереднього розтягу, визваного впливом часу, на згинально-крутильну стійкість. Параметри що розглядалися: - вік бетону під час першого навантаження; тривалість навантаження; - міцність бетону та сталі; - коефіцієнт гнучкості; - відношення висоти арки до іiі прольоту, та їх вплив на деформації повзучості трубобетонних арок. Зроблено висновок, що тимчасові ефекти виявляють значний вплив на поперечну стійкість тонких параболічних арок $з$ низькою міцністю сталі і високим відношенням прольоту до стріли підйому, які навантажені рівномірно розподіленим навантаженням в ранньому віці та знаходяться довгий час під навантаженням.

Цілі і завдання. Виконати огляд досліджень по визначенню сучасних конструктивних рішень великопролітних трубобетонних аркових мостів і зробити їх порівняння 3 існуючими арковими мостами. Отримати габаритні параметри та застосовані матеріали і конструкції для різних розрахункових схем.

Основна частина. Конструктивні рішення сучасних трубобетонних аркових мостів постійно змінюються. Визвано це необхідністю збільшення габаритних розмірів споруд, а також впровадженням в будівництво нових надміцних матеріалів та наукових розробок [5-7].

Трубобетон не тільки міцний та стійкий до навантажень конструкційний матеріал, але і економний в процесі виготовлення та експлуатації. Особливо в аркових спорудах з трубобетону отримується міцність за рахунок форми. Металева труба $€$ зовнішньою поверхнею конструкції що будується і може мати різну обробку, виконану в заводських умовах. Виготовлення опалубки з металевих труб дозволяє робити розміри, форму і конфігурацію різними в залежності від вимог проекту.

Для аналізу конструктивних характеристик трубобетонних великопролітних мостів обрані мости 3 прольотом більше 300 м. Типи 
поперечних перерізів трубобетонних арок показані на рис. 1. В таблиці 1 наведено побудовані мости, де наведено габаритні розміри арок, а також конструкцію їх поперечного перерізу.

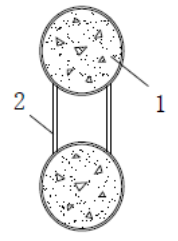

a

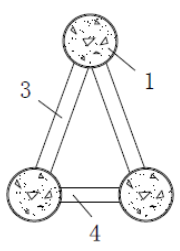

б

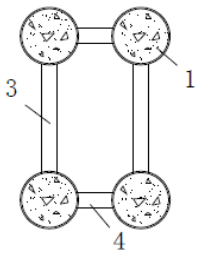

B

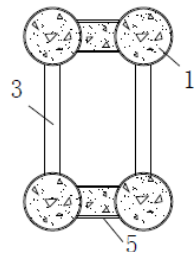

$\Gamma$

Рис. 1. Типи поперечних перерізів трубобетонних арок:

а) двотрубна; б) трьохтрубна; в) і г) чотирьохтрубна;

1 - металева труба заповнена бетоном; 2 - вертикальна металева пластина;

3 - ферма; 4 - горизонтальний елемент з'єднання; 5 - горизонтальна металева пластина.

Таблиця 1

Трубобетонні аркові мости прольотом понад $300 \mathrm{M}$

\begin{tabular}{|c|c|c|c|c|c|c|c|}
\hline \multirow[b]{2}{*}{ № } & \multirow{2}{*}{ Назва мосту } & \multirow{2}{*}{ 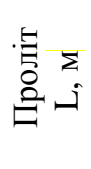 } & \multirow{2}{*}{ 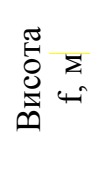 } & \multirow{2}{*}{$\mathrm{L} / \mathrm{f}$} & \multicolumn{2}{|c|}{ Труба } & \multirow{2}{*}{ Тип арки } \\
\hline & & & & & $\begin{array}{l}\mathrm{D}, \\
\mathrm{MM}\end{array}$ & $\begin{array}{c}\mathrm{t}, \\
\mathrm{MM}\end{array}$ & \\
\hline 1 & 2 & 3 & 4 & 5 & 6 & 7 & 8 \\
\hline 1 & He River №1 & 529 & 117 & 4,5 & 1320 & 30 & 4 трубна \\
\hline 2 & Wushan & 460 & 121 & 3,8 & 1220 & 25 & 4 трубна \\
\hline 3 & Zhijing & 430 & 78 & 5,5 & 1200 & 35 & 8 трубна \\
\hline 4 & Liancheng & 400 & 77 & 5,2 & 850 & 26 & 6 трубна \\
\hline 5 & Yellow River & 380 & 76 & 5 & 1500 & - & 4 трубна \\
\hline 6 & Maocaojie & 368 & 74 & 5 & 1000 & 28 & 4 трубна \\
\hline 7 & Yajisha & 360 & 80 & 4,5 & 750 & 20 & 6 трубна \\
\hline 8 & Yong $\mathrm{He}$ & 338 & 75 & 4,5 & 1220 & 25 & Горизонт. \\
\hline 9 & Xiao He & 338 & 68 & 5 & 1100 & 32 & 6 трубна \\
\hline 10 & Tai Ping $\mathrm{Hu}$ & 336 & 68 & 4,9 & 1280 & 25 & Горизонт. \\
\hline
\end{tabular}

В Китаї розроблено Технічний кодекс для трубобетонних аркових мостів GB 50923-2013 [8]. В ньому трубобетонні аркові мости поділяються на п'ять основних типів (рис. 2). 
a)
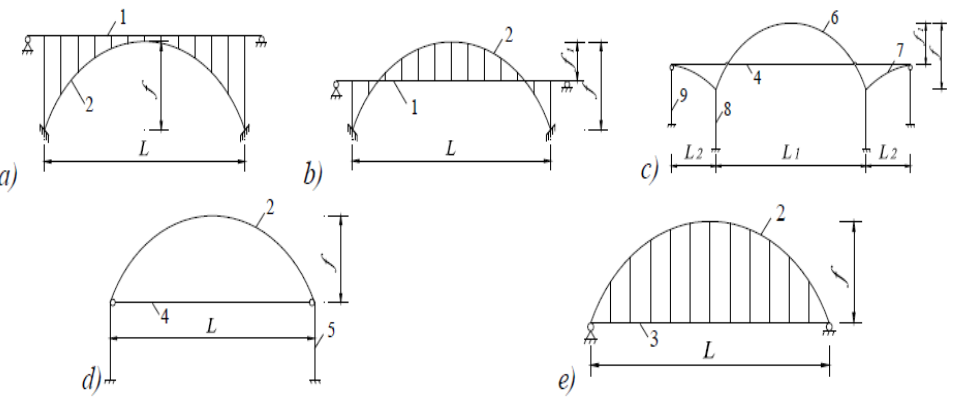

Рис. 2. Основні типи конструкцій трубобетонних арок

a) палубна арка; b) арка з їздою по середині; с) арка в вигляді летючого птаха; d) жорстка арка з гнучкою затяжкою; е) арка, закріплена палубою.

На основі аналізу рельєфу та геології майданчику будівництва моста було запропоновано три схеми для варіантного проектування [9]. Схеми обрані такі:

- висячий міст прольотом 520 м (рис.3, схема 1);

- металевий коробчастий арковий міст прольотом 518 м (рис. 4, схема 2);

- трубобетонний арковий міст прольотом 530 м (рис.5, схема 3).

Техніко-економічне порівняння трьох варіантів мостів наведено в табл. 2.

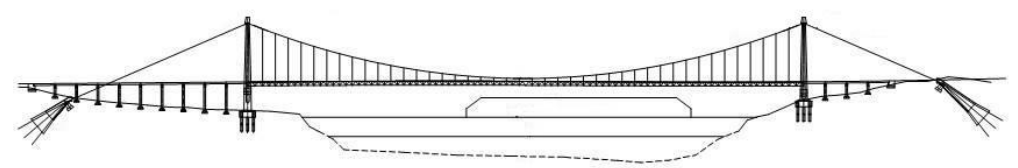

Рис. 3. Висячий міст прольотом 520 м (схема 1)

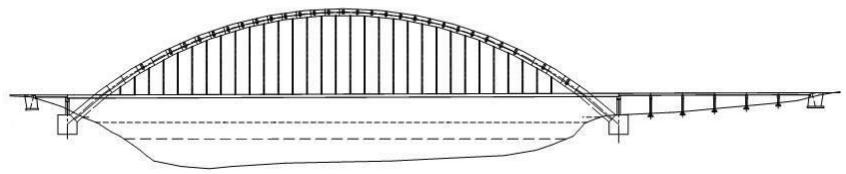

Рис. 4. Металевий коробчастий арковий міст прольотом 518 м (схема 2)

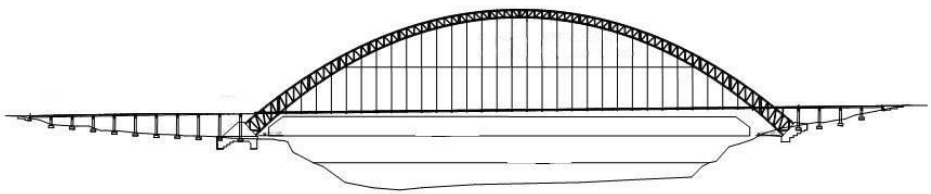

Рис. 5. Трубобетонний арковий міст прольотом 530 м (схема 3) 
Таблиця 2

Техніко-економічні порівняння трьох варіантів мостів

\begin{tabular}{|l|c|c|c|}
\hline Показники моста & $\begin{array}{c}\text { Схема 1 } \\
\text { (рис. 3) }\end{array}$ & $\begin{array}{c}\text { Схема 2 } \\
\text { (рис. 4) }\end{array}$ & $\begin{array}{c}\text { Схема 3 } \\
\text { (рис. 5) }\end{array}$ \\
\hline Загальна довжина, м & 810 & 750 & 841 \\
\hline Основний проліт, м & 520 & 518 & 530 \\
\hline Під'їзди, м & 290 & 232 & 311 \\
\hline Надміцна сталь, т & 3304 & 148 & 724 \\
\hline Звичайна сталь, т & 9455 & 23694 & 12441 \\
\hline Бетон, м & 43344 & 29400 & 37900 \\
\hline Витрати, млн. доларів & 310,87 & 493,83 & 250,30 \\
\hline
\end{tabular}

Оцінюючи конструктивні рішення варіантів мостів, можна виділити їх недоліки. Схема 1 (рис. 3). Використання великої кількості надміцної сталі, більш висока вартість ремонту та обслуговування. Схема 2 (рис. 4). Використання великої кількості сталі, складність конструкції, висока вартість будівництва, висока вартість ремонту та обслуговування. Схема 3 (рис. 5). Більш складні будівельні роботи.

Порівняння проекту трубобетонного моста (схема 3, рис. 5) виконаємо з існуючим мостом №2 з таблиці 1. Проліт мосту через річку Хецзян Янцзи на 70 м довший від моста Ушань, а висота арки на 10 м нижча, що ускладнює заливку бетону зі збільшенням прольоту. В проектованого мосту простіший підйом елементів, хоча їх вага на $600 \mathrm{\kappa H}$ більша. Ширина перекриття палуби складає 9 м, а вага перекриття зменшилася на $42 \mathrm{\kappa H} / \mathrm{m}^{2}$ за рахунок застосування ортогональної ребристої плити з залізобетону. В арках проекту використані труби діаметром 1320 мм, що на 100 мм більші ніж у мості Ушань.

В основному великопролітні трубобетонні аркові мости побудовані для автомобільних доріг, але вже завершено будівництво моста прольотом 430 м і для залізниці Лхаса - Ньінчі [10]. В майбутньому великопролітні аркові трубобетонні мости планується використовувати для високошвидкісної залізної дороги. Такий міст з жорстким каркасом найкраще використовувати для високошвидкісної залізної дороги з-за його великої жорсткості, нечутливості до добових коливань температури та хорошої довговічності. Завдяки легким конструктивним елементам i раціональній розрахунковій схемі аркові трубобетонні мости доцільно будувати в гірських районах і для перетину каньйонів, де вони більш ефективні ніж висячі або вантові мости великих прольотів.

Навіть при тому, що досягнуті успіху в проектуванні і будівництві аркових трубобетонних мостів, існуючі технології все ще не можуть задовольнити сучасні потреби. Таким чином, необхідно постійно вести пошук нових конструктивних рішень та розв'язувати важливі питання по підвищенню характеристик втомлюваності зварних з'єднань, оптимізації 
сегментів бетонування, подальшого зниження ваги конструкції, що сприяє збільшенню довжини прольоту. Можливість будівництва трубобетонного аркового мосту польотом 650 м вже доказана і ведеться проектування мосту прольотом $700 \mathrm{M}$.

Висновки і перспективи досліджень. Розглянуто велику кількість мостів із застосуванням трубобетонних арок, вивчені їх конструктивні рішення та виконано аналіз. Можна зробити висновок, що на сьогоднішній день не існує єдиної методики по проектуванню досить перспективних аркових мостів, тому ця проблема $є$ актуальною і потребує подальшого вивчення.

\section{Список використаних джерел}

1. Adao da Fonseca A. Contemporary concrete arch bridges / A. Adao da Fonseca // ARCH'16 - 8th International Conference on Arch Bridges, Wrocław, Poland, 5-7 October, 2016: 1-14.

2. Adao da Fonseca A. The Infant Dom Henrique Bridge over the River Douro, at Porto / A. Adao da Fonseca // ARCH'07 - 5th International Conference on Arch Bridges, Madeira, Portugal: University of Minho Press, 2007: 931-960.

3. Candrlic V. Research of Concrete Arch Bridges up to 1000m in Span / V. Candrlic, J. Radic, I. Gukov // ARCH'04 - 4th International Conference on Arch Bridges, Barcelona, Spain, November, 2004: 38-52.

4. Yue Geng. Time-dependent behavior of concrete-filled steel tubular arch bridges. Dissertation submitted to the in fulfilment of the requirements for the degree of Doctor of Philosophy School of Civil Engineering The University of Sydney Australia. Sydney, 2011.

5. Chen B.C. Application of concrete filled steel tubular arch bridges and study on ultimate load - carrying capacity / B.C. Chen, Y.J. Chen, Z.B. Qin, H. Hikosaka // ARCH'04 - 4th International Conference on Arch Bridges, Barcelona, Spain, November, 2004: 38-52.

6. Chen B.C. Overview of Concrete Filled Steel Tube Arch Bridges in China / B.C. Chen, T.L. Wang // Practice Periodical on Structural Design and Construction, ASCE, May, 2009. 14(2): 70-80.

7. Developments and advanced applications of concrete-filled steel tubular (CFST) structures: Members / Lin-Hai Han, Wei Li, Reidar Bjorhovde // Journal of Constructional Steel Research 100 (2014) 211-228.

8. Chen B.C. China National Standard Technical Code for CFST Arch Bridges / B.C. Chen, J.G. Wei, Q.X. Wu // ARCH'16 - 8th International Conference on Arch Bridges, Wrocław, Poland, 5-7 October, 2016: 363-374. - C.44-56.

9. Mou T.M. Scheme design of a 530m CFST arch bridge - the First Yangtze River Bridge in Hejiang, Sichuan, China / T.M. Mou, B.K. Fan, B. Tian and Q.Y. Tao // ARCH'10 - 6th International Conference on Arch Bridges, Fuzhou, China, 11-13 October, 2010: 113-119.

10. Zheng Jielian. Concrete-Filled Steel Tube Arch Bridges in China / Jielian Zheng, Jianjun Wang // Engineering 4 (2018) 143-155. 